\title{
A Study on College Students' Oral English Skills Based on Scaffolding Theory
}

\author{
Ming Cai \\ School of Foreign Languages \\ Xinyang Agriculture and Forestry University \\ Xinyang, China
}

\begin{abstract}
This paper focuses on scaffolding and its application to college students' oral English with the point of view of constructivism. Taking the classroom teaching design of oral English class as an example, this paper discusses how to use scaffolding theory to organize college students' oral English teaching.
\end{abstract}

keywords—scaffolding; oral English; college students

\section{INTRODUCTION}

Scaffolding, namely through teacher's help shifts the learning management task from the teacher to the students themselves. In scaffolding, teachers as the culture, representing teaching guide the student to master and internalize those skills which can prompt them to engage in higher cognitive activities. The ability of mastery and internalization is consistent with their age and cognitive level, but once the learners develop these skills, they can go on for more self-regulated learning.

Since the advent of scaffolding theory, it attracts the attention of linguistics both at home and abroad. Not only does it have great theoretical value, but also owns extensive application value in foreign language teaching. J. Piaget thinks, children with surrounding environment are in the process of interaction and gradually construct knowledge about the external world of cognitive structure, thus make their own cognitive process develop from assimilation and accommodation and suffer from balance to imbalance and then to a new balance process. (Ovando, C., 2003, p.21) In the 1930s Soviet psychologist, educator Lev S. Vygotsky put forward the important thought concerning the development of teaching and proximal development based on social-culturehistory theory, namely Zone of Proximal Development, ZPD. Lev S.Vygotsky thinks, there are at least two kinds of development levels in children' s intellectual development, the existing development level and potential development level. It is the region that between the two development levels is called Zone of Proximal Development by Vygotsky. On the basis of the ZPD, Btuner, Wood and Mercer proposed the theory of scaffolding.

This paper focuses on scaffolding theory of college English teaching. The specific innovation points are based on scaffolding' s own advantages and the objective need of college students in oral English teaching to explore the applicability and operability of scaffolding. This paper is divided into five parts, the first part for introduction, the second part explain the scaffolding in constructivist teaching mode in detail. The third part clarifies the application of scaffolding in college students' oral English teaching, which provides the premise for the experimental section. The fourth part, the key of this paper, through specific experiments proves the specific applications and implementing effects of scaffolding theory in college students, thereby, it obtains the conclusion from the fifth part.

In oral English class, the frequency of students' oral Engish speaking is too low, and they practise the dialogue with fixed sentence patterns instead of setting in the simulated situation to communicate. In such oral English class, the students only learn the language form, the structure of language, but not the actually grasp of language communicative means, the function of oral English ability, and the training effect is not satisfactory (Piaget, J., 1992, p.18) Finally, the oral English ability of students improves slowly. How to make the students in practical application of language, how to activate their stock, how to consolidate the language rule already learned and how to acquire the new expression are currently the main problems of college students in oral English. In view of this situation, this article attempts to construct socialist learning theory as the guide, and explores scaffolding of oral English teaching in college students and application of scaffolding in class teaching design.

\section{SCAFFOLDING THEORY ROOTED IN THE LEARNING MODE OF CONSTRUCTIVISM}

\section{A. Study and Teaching Theory of Constructivism}

Constructivism, called the structuralism once, is a branch of cognitive theory. Constructivism is the further development from behaviorism to cognitivism in learning theory. The latest teaching theory of pedagogical psychology was proposed by the most influential Swiss psychologist J. Piaget in the 1960s. It is consistent with quality education. In short, it can form a relatively effective new cognitive learning theory under the guidance of structuralism theory, and on the basis of this theory it will achieve ideal constructivism learning environment. Hereby, the author will make a brief explanation of the basic content in constructivism learning theory from two aspects, learning theory and learning method.

Constructivism holds that learning is not simply direct inputting information from inside to outside, but the interaction process among new information, learners and learning 
environment. In the process, each learner recognizes and codes the new information based on the experience of their understanding. Meanwhile, the original knowledge will change because of new experience intervention.Therefore, how much knowledge the learners gain depends on the ability of constructing knowledge themselves according to their own experience, not the memory and reciation abilities.

\section{B. The Scaffolding under the Mode of Constructivism}

For oral English teaching on how the language input and output, constructivism put forward a definite teaching method, Scaffolding . Scaffolding is used to be the industry scaffolding in the construction. Constructivism use it to describe study to understand the concept framework. Scaffolding teaching method, around the current theme for learners, provides a conceptual framework (namely a facilitate climbing scaffold) and guides the students to enter a certain problem situation. This lets the students explore independently and learn collaboratively, so that the students themselves, as the scaffolding in conceptual framework, rise ceaselessly. Gradually, through the stents the teachers shift management control study to the students, and remove the stents at last.

"Scaffolding" should be a complete concept system, and the starting point is not the knowledge students have already mastered but the knowledge level slightly higher than existing knowledge. This difference is Zone of Proximal Development. Thus the two development levels are decided by teaching, namely, teaching can create proximal development zones. Therefore, in Scaffolding, teachers should build up the reasonable "scaffolding" according to the intelligence and comprehension of the proximal development zone of the students. By the scaffolding role, teachers help the students' intelligence constantly promote from one level to another new higher level, and accomplish truly to make teaching move on in front of development.

Scaffolding is composed by five links:

- Take the scaffolding: set the conceptual framework around the current study theme by the requirements of proximal development zones.

- Enter the situation: guide the students into certain problem situations.

- Explore independently: let the students explore independently. Exploration content: make sure the related attributes of given concepts and list the related attributes in order of importance. In the beginning, the teachers inspire firstly, and then let the student to analyze. In the exploration process, teachers should hint timely and help students rise step by step along the conceptual framework. At first teacher' s guidance will be frequent, but gradually reduce later. More and more chances will be given to students themselves to fight for exploration. Finally, the students can climb up in conceptual framework without teachers' guidance.

- Cooperative learning in group: prompt the contradictions of consultation and discussion moderate. The results of discussion are likely to change the former order. This helps the conflicting and complex situation gradually become clear and consistent. Understanding the former concepts on the basis of collective minds successfully is the completely significant step of constructing the knowledge. Therefore, collaborative learning plays an important role in knowledge construction.

- Effect evaluation: the effects contain students' self evaluation, group learning evaluation, and teachers' evaluation. And the content of evaluation has three aspects, a. autonomous learning ability b. contributions to cooperative learning $c$. whether complete the construction of knowledge or not.

According to the characteristics of college students' oral English learning and the Scaffolding under constructivism modes, the author thinks that, we can use the Scaffolding under the constructivism modes when we design courses, which is undoubtedly a beneficial attempt.

\section{APPLICATION OF THE SCAFFOLDING THEORY IN ORAL ENGLISH OF COLLEGE STUDENTS}

Scaffolding is based on the theory of Lev S. Vygotsky, Zone of Proximal Development. In his view, among the children' s intelligent activities, the difference between problem-solving ability and original ability may be eliminated through teaching with the help of the teacher.

\section{A. The Advantages of the Scaffolding}

Scaffolding emphasizes the creation of study situation and the subject of learners. Independent exploration with the idea of cooperative communication accord with the request of oral English teaching, because it can effectively guide each section of oral English teaching activities. It displays in:

1) Scaffolding emphasizes students-centered learning under the guidance of teachers: All the teaching designs are around "learning" and the students' activities spread throughout the oral English classes. This highlights the characteristics in language learning, and gives full play to students' initiative on account of internalizing the linguistic structure in different contexts and formatting the language ability to solve practical problems

2) Using scaffolding theory gives effective guidance for the classroom activities: Teachers can set up different problems according to the teaching material content in different teaching links, and build up different levels of stents and provide timely help and guidance. This action benefits the students in getting assimilation and adaptation in classroom communication process, students rise step by step along the scaffolding and finally complete the language construction.

3) In classroom activities, students need to construct knowledge through collaborative learning, which is neglected by the traditional teaching methods: For students, personal explorations promote the ability to analyze problems, and the collaborative learning is helpful for problem-solving. The learning process is the process of communication. The interaction between students and the surrounding environment is not only beneficial to deepen the understanding of the 
learning contents, but also promote the development of communicative ability.

\section{B. The Objective Needs of the Oral English Teaching}

Language, the thought form of expression, exists and develops in the practical application, but the thought is diversified and unpredictable. Therefore, in language teaching, including oral English teaching, the teachers don' $t$ need to teach students every word that may apply in communication, it is impossible and unnecessary. Instead, teaching the students the basic language structures and learning methods enable them to express their thoughts flexibly in actual use. In addition, the process of the second language learning involves in the internalization of linguistic structure. The so-called internalization refers to the process rising from the knowledge level to ability level process in structure of language, vocabulary and idiomatic expression. On the one hand, students have to learn how to use the language system constructing speech materials in expressing the thought, it makes the abstract language rules internalize as a deep language pattern; On the other hand, and students need to learn new language materials from discourse, thus construct an individual mastered language system. When the students understand the new discourse, they also learn a new language material and try to use these new language materials to construct a new discourse. Therefore, the language skill and speech ability get synchronous development. In the final analysis, the process of a second language learning is also the process of language construction. Fundamentally, language is not to be taught, but learned and understood. This is the view of emphasizing that the self-constructivism learning is the ultimate goal of learning. According to the teaching goal, students should have the ability of flexibly choosing different styles, structures and tones according to different objectives, occasions in real communication. To meet the requirement of this goal to college students will not be easy. As we are known, oral communication ability mainly includes two aspects, language rules and language application skills. Although the college students have grasped some certain language rules, they are often in a static saving state for the second language knowledge, that is to say, they can apply with the second language flexibly in need of use. The main task of an oral English teacher is to think out a way of helping the students to use the language rules to express their thoughts freely. Noticefully, the college students have a strong desire of speaking and demanding, so does the ego recognition consciousness. They're more likely attempting to popularize the mastered the language knowledge to other context, not to follow the teacher repeat and to imitate mechanically. Therefore, on oral English teaching, the teacher may borrow the construction and build up a support of language structure to provide a simulated real situation. Students claim upward along the stents constantly, so that they have the opportunity combine and apply the learned and related language knowledge in a specific context. Using the language flexibly and making this ability to be sustained development will eventually promote the development of the students' thoughts.

\section{SPECIFIC APPLICATION AND IMPLEMENTING EFFECTS OF SCAFFOLDING}

"Oral English teaching is the key training at the new language structure to achieve a certain proficiency for communication." Hence, in oral English teaching, teachers should base the colloquial discourse on textbooks, and build up a stent for the student according to the principle of "Zone of Proximal Development". And then the students communicate around the topics related to the language structure in order to cultivate the students' communicative competence. In that case, students can combine the knowledge have already learned with the knowledge just learned flexibly.

The author will take the college English textbooks, the fifth unit, for example, and discuss how to use Scaffolding to oral English teaching. The topic of this textbook is "life in the city and in the country". On this topic, teachers should build up a conceptual framework: how to ask others on something, how to express the view clearly, how to refute the different points of view, and how to establish a new view.

\section{A. Implementing Strategies}

The implementing strategies include four processes. There are setting the context, entering the context, independent investigation, textbooks imitation and communication practice in groups.

Setting the Context: To (1) Design a question at first, cause the student to have a perceptual cognition to the central subject. The actual problem is based on the existing knowledge to make sure that the content and student's life are closely linked. Because most colleges are in the countryside, the topic begins with "Are you going to work in the countryside after your graduation from university?" In the beginning, most students answered "No". Ask continuously, "Why not? Why not live in the city?" A hot discussion starts in class.

Adopt the form of teacher-students dialogue, check and acknowledge students' views, and then put forward a question concerned with the activity content.author/s of more than two affiliations:

Q1: How do the teachers and students to ask about people's points of view just now? Are their answers consistent?

Q2: How do they express their views?

Write down the used language structure just now on the blackboard.

Asking for opinions Giving opinions
A. What do you think of...?
B. Do you like...?
C. Which do you prefer...?
D. What's your opinion of...?
E. I think...
F. I guess $\cdots$ 
According to the current theme and students' expression ability, the teacher sets a situation and lets the students speak freely and discuss the content related to the topic. Combining the material related to students' experience and specific situations will form background experience and raise the students' interest to discuss and desire to communicate. Through this process, students acknowledge the new language and understand the barriers in language expression.

\section{B. Independent Investigation}

(1) Through the questions, the teacher inspires the students to notice the ability of language and communication in conversation, guides the student to explore independently, comprehends the newly-emergenced language structure.

Q: How many language structures do you find in dialogue among speakers? What's your opinion? Which language structure have we already learned? Which are new for us?

(2) The teacher gives time to students for independent exploration, and then lets the student sum up the new language structure. This helps the students consolidate existing knowledge and deepen the impression for new knowledge, thus acquire new expression methods.

(3) Interpretation of the new language structure. For the emergence of new language structure, it is better to let the students explore and grasp independently, then the teacher makes proper explainations. Concequently, it can pave ways for furthur communication along the stents. Students can deepen the understanding of the subject in the process of understanding and analyzing the new knowledge, thus students complete assimilation and adaptation.

\section{The Implementing Effects and Evaluation}

- Personal assessment: whether the students complete the sense of construction.

- Team assessment: study groups evaluate in accordance with the contribution of each member, complement mutually, and complete knowledge constructing.

- Teachers evaluation: teachers evaluate study groups and individuals to grasp the existing problems for the preparation of the newly-builded "Zones of Proximal Development."

\section{CONCLUSION}

In summary, the research tells us that the evidence collected in the research implicates that scaffolding as an idea of teaching and learning may lead our practice of English teaching and learning in colleges to a more rational and promising way of cultivating all-round English abilities in the end rather than tests. Accordingly, students would like to develop their oral communicative competence on purpose while the teacher is trying his or her best to provide affective support for them, demand attention, convey expectations and simplify the task to be accomplished. The research shows that it should be necessary to popularize the theory of constructivism and Scaffolding theory in teaching and encourage teachers to innovate their teaching practice with scaffolding.
However, the research has the following shortcomings. Firstly, improving oral communication can not be successful in such a short term of competence experiment. Secondly, we can not compare the results of the class with Scaffolding and the results of the class without Scaffolding theory synchronically because there is no control class. Thirdly, although discourse analysis can explain and explore more impacts of various scaffolding on students' oral communicative competence, qualitative data cannot be video-taped for discourse analysis in this study. Even though the study has its own limitations, it still contributes to the knowledge regarding effective pedagogy for fostering oral communicative competence in college English teaching based on the theory of constructivism. It may also serve as the springboard to future research possibilities concerning Scaffolding theory.

\section{ACKNOWLEDGMENT}

Special gratitude goes to my students for their support and cooperation throughout the whole research and teaching. And sincere gratitude goes to my beloved family. Without their support, I could not have come so far.

\section{REFERENCES}

[1] Cazden, C. B. Classroom Discourse. Portsmouth, NH: New Hamshire Press, 1998.

[2] Diane, L. M. and R. L. Michael. An Introduction to the Second Language Acquisition Research. London: London Psychology Press, 2000. K. Elissa, "Title of paper if known," unpublished.

[3] Krashen, S. The Input Hypothesis: Issue \& Implication. New York: Longman Teaching and Research Press, 1985.

[4] Ovando, C. Bilingual Education in the United States: Historical Development and Current Issues. San Francisco: W. H. Freeman, 2003.

[5] Piaget, J. The Psychology of the Child . New York: Guilford Press, 1992.

[6] Stake, R. E. The Art of Case Study Research. Beijing: Foreign Language Teaching and Research Press, 1995. 